\title{
Desenvolvimento inicial de variedades de cana-de-açúcar em Latossolo submetidas a níveis de compactação do solo
}

\author{
Eliane A. A. Fagundes ${ }^{1}$, Tonny J. A. da Silva ${ }^{2} \&$ Edna M. Bonfim-Silva ${ }^{3}$ \\ ${ }^{1}$ ICAT/UFMT. Rondonópolis, MT. Fone: (66) 3410-4017. E-mail: elifagundes_@hotmail.com \\ ${ }^{2}$ ICAT/UFMT. Rondonópolis, MT. Fone: (66) 3410-4063. E-mail: tonny.silva@pq.cnpq.br \\ ${ }^{3}$ ICAT/UFMT. Rondonópolis, MT. Fone: (66) 3410-4063. E-mail: embonfim@hotmail.com (Autor correspondente)
}

Palavras-chave:

densidade do solo

Saccharum officinarum L.

desenvolvimento de plantas

\begin{abstract}
R E S U M O
Objetivou-se, neste trabalho, avaliar o desenvolvimento inicial de três variedades de cana-de-açúcar (RB002504, RB867515 e RB931011) em cinco níveis de densidade do solo (1,0;1,2; 1,4;1,6 e 1,8 $\left.\mathrm{Mg} \mathrm{m}^{-3}\right)$. O trabalho foi desenvolvido em casa de vegetação, na Universidade Federal de Mato Grosso, Campus Universitário de Rondonópolis, com delineamento de blocos casualizados composto de esquema fatorial 3 x 5 correspondente a 3 variedades e 5 níveis de compactação e quatro repetições. Foram avaliadas as variáveis: número de perfilhos, número de folhas, área foliar, massa seca das folhas, comprimento de colmos, massa seca de colmos e altura de planta. Os dados obtidos foram submetidos ao teste F para comparação das médias, ao teste de Tukey a 0,05 de probabilidade para as variedades e regressão polinominal para densidades. Conclui-se que a variedade RB002504 apresenta bom perfilhamento, mas não apresenta bom desenvolvimento de colmos. A variedade RB867515 apresenta bom desenvolvimento de área foliar mostrando boa adaptação ao solo estudado e a variedade RB931011 se destaca na parte aérea e no desenvolvimento de colmos.
\end{abstract}

Key words:

soil density

Saccharum officinarum L.

plant development

\section{Initial development of varieties of sugarcane in Oxisol subjected to levels of soil compaction}

\begin{abstract}
A B S T R A C T
The objective of this study was to evaluate the initial development of three varieties of sugarcane (RB002504, RB867515 and RB931011) in five levels of soil density $\left(1.0 ; 1.2 ; 1.4 ; 1.6\right.$ and $\left.1.8 \mathrm{Mg} \mathrm{m}^{-3}\right)$. The study was conducted in a greenhouse at the Federal University of Mato Grosso, Campus of Rondonópolis in randomized block design consisting of $3 \times 5$ factorial scheme corresponding to 3 varieties of sugarcane and 5 levels of soil compaction and four replications. The evaluated variables were number of tillers, number of leaves, leaf area, dry mass of leaf and stem, stem length and plant height. The data were submitted to $F$ test at 0.05 of probability and for comparison of means by the Tukey test for varieties and polynomial regression for densities. The variety RB002504 showed good tillering, but not good development of stems. The variety RB867515 showed good development of leaf area showing good adaptation to the studied soil while variety RB931011 stood out in stem development.
\end{abstract}

\section{INTRODUÇÃo}

A cana-de-açúcar (Saccharum officinarum L.) é uma gramínea geralmente cultivada em áreas tropicais ou subtropicais, originária do Sudeste Asiático e classificada segundo Cronquist (1981) em Divisão Manoliophyta, Classe Magnoliopsida, Ordem Graminales, Família Poaceae Gênero Saccharum.

O Brasil é o maior produtor mundial de cana-de-açúcar com produção de 698 milhões de toneladas em 8,8 milhões de hectares; o segundo maior produtor mundial é a Índia, seguida da China, Tailândia e Paquistão. De toda a cana-deaçúcar produzida no Brasil cerca de 652 milhões de toneladas são empregados na fabricação de álcool e açúcar (FNP, 2011).

O Estado de Mato Grosso teve sua área plantada com canade-açúcar aumentada em 16 mil hectares totalizando 220 mil ha de área plantada em 2011, o que demandou uma grande necessidade de genótipos para a implantação das novas áreas de produção no Estado. A expansão do plantio desta cultura se deve principalmente à escassez das reservas de combustíveis fósseis demandando buscas por combustíveis alternativos.

A compactação do solo pode induzir alterações na absorção e concentração de nutrientes nas plantas e, em consequência, em seu desenvolvimento. De acordo com Bonelli et al. (2011) a produção de colmo, folha e a relação folha/colmo de gramíneas são afetadas pela compactação do solo.

O cultivo de cana-de-açúcar condicionado ao tráfego de máquinas para colheita e quando em situações de solo com elevados conteúdos de água, pode levar ao aumento da compactação em decorrência da colheita mecanizada (Severiano et al., 2009). Assim, torna-se importante o conhecimento da adaptação de diferentes cultivares em cada ambiente buscando 
o aumento da produtividade e a obtenção de características exigidas pela indústria sucroalcooleira. Segundo Machado et al. (1982) a análise de crescimento é considerada o primeiro passo da análise de produção vegetal.

Objetivou-se, com o presente estudo, avaliar o crescimento e o desenvolvimento do estádio inicial de variedades de cana-de-açúcar em níveis de compactação em Latossolo Vermelho do cerrado.

\section{Material e Métodos}

O trabalho foi desenvolvido na área experimental de pesquisa do Programa de Pós-Graduação em Engenharia Agrícola, na Universidade Federal de Mato Grosso, Campus de Rondonópolis, MT, em casa de vegetação. A umidade do ar na casa de vegetação ficou em torno de $59 \%$ e a temperatura média era de $28^{\circ} \mathrm{C}$. De acordo com a classificação de Koppen, o clima da região é AW - Clima tropical com estação seca no inverno.

O experimento foi conduzido no período de agosto a dezembro de 2011 cujo solo utilizado foi Latossolo Vermelho, textura franco-arenosa, coletado na camada de $0-20 \mathrm{~cm}$, em área de cerrado. Para a instalação do experimento o solo foi peneirado em malha de $4 \mathrm{~mm}$ e posteriormente acondicionado em sacos plásticos contendo $12 \mathrm{dm}^{-3}$ de solo.

A caracterização química e granulométrica do solo apresentou os seguintes resultados: $\mathrm{pH}\left(\mathrm{em} \mathrm{CaCl}_{2}\right)=4,1 ; \mathrm{Al}$ trocável $\left(\mathrm{cmol}_{c}\right.$ $\left.\mathrm{dm}^{-3}\right)=1,1 ; \mathrm{Ca}\left(\mathrm{cmol}_{\mathrm{c}} \mathrm{dm}^{-3}\right)=0,3 ; \mathrm{Mg}\left(\mathrm{cmol}_{\mathrm{c}} \mathrm{dm}^{-3}\right)=0,2 ; \mathrm{P}$ (Mehlich 1) $\left(\mathrm{mg} \mathrm{dm}^{-3}\right)=2,4 ; \mathrm{K}\left(\mathrm{mg} \mathrm{dm}^{-3}\right)=28 ; \mathrm{S}\left(\mathrm{mg} \mathrm{dm}^{-3}\right)$ $=6,8$; Matéria orgânica $\left(\mathrm{g} \mathrm{dm}^{-3}\right)=22,7 ; \mathrm{V}(\%)=6,5$; Argila $(\mathrm{g}$ $\left.\mathrm{kg}^{-1}\right)=367$; Areia $\left(\mathrm{g} \mathrm{kg}^{-1}\right)=549$; Silte $\left(\mathrm{g} \mathrm{kg}^{-1}\right)=840$. De acordo com a caracterização do solo realizou-se aplicação de calcário dolomítico com objetivo de elevar a saturação por bases para $60 \%$.

As adubações de plantio foram realizadas aplicando-se $30 \mathrm{~kg} \mathrm{ha}^{-1}$ de N, $200 \mathrm{~kg} \mathrm{ha}^{-1}$ de $\mathrm{K}_{2} \mathrm{O}$ e $180 \mathrm{~kg} \mathrm{ha}^{-1}$ de $\mathrm{P}_{2} \mathrm{O}_{5}$, na forma de ureia, cloreto de potássio e superfosfato simples, respectivamente. A recomendação de adubação foi estabelecida de acordo com as normas do Boletim Técnico 100 (Raij et al., 1996) e aplicada diretamente dentro dos sacos plásticos.

A unidade experimental foi constituída pela sobreposição e encaixe de três aneis de PVC rígido com diâmetro de $200 \mathrm{~mm}$, em que cada anel media $100 \mathrm{~mm}$ de altura; na parte inferior da unidade experimental havia uma tela de polietileno com malha de $1 \mathrm{~mm}$, fixada com anel de borracha obtido pela secção transversal de câmara de ar utilizada em pneus de caminhão.

No encaixe dos anéis foi realizada uma fixação com fita adesiva (Figura 1); pratos plásticos de $300 \mathrm{~mm}$ de diâmetro foram colocados embaixo de cada unidade experimental para servir como fundo do recipiente.

Os aneis superiores e inferiores foram preenchidos com massa de solo equivalente para manter a densidade de $1,0 \mathrm{Mg} \mathrm{m}^{-3}$ enquanto $o$ anel central foi mantido com os níveis de compactação de acordo com os tratamentos (1,0; 1,2; 1,4; 1,6 e 1,8 $\left.\mathrm{Mg} \mathrm{m}^{-3}\right)$.

A massa de solo destinada ao anel mediano foi compactada com a utilização de uma prensa hidráulica modelo P15ST, marca BOVENAV. Ensaios prévios de compactação em laboratório (ensaio de proctor normal) foram realizados para determinação
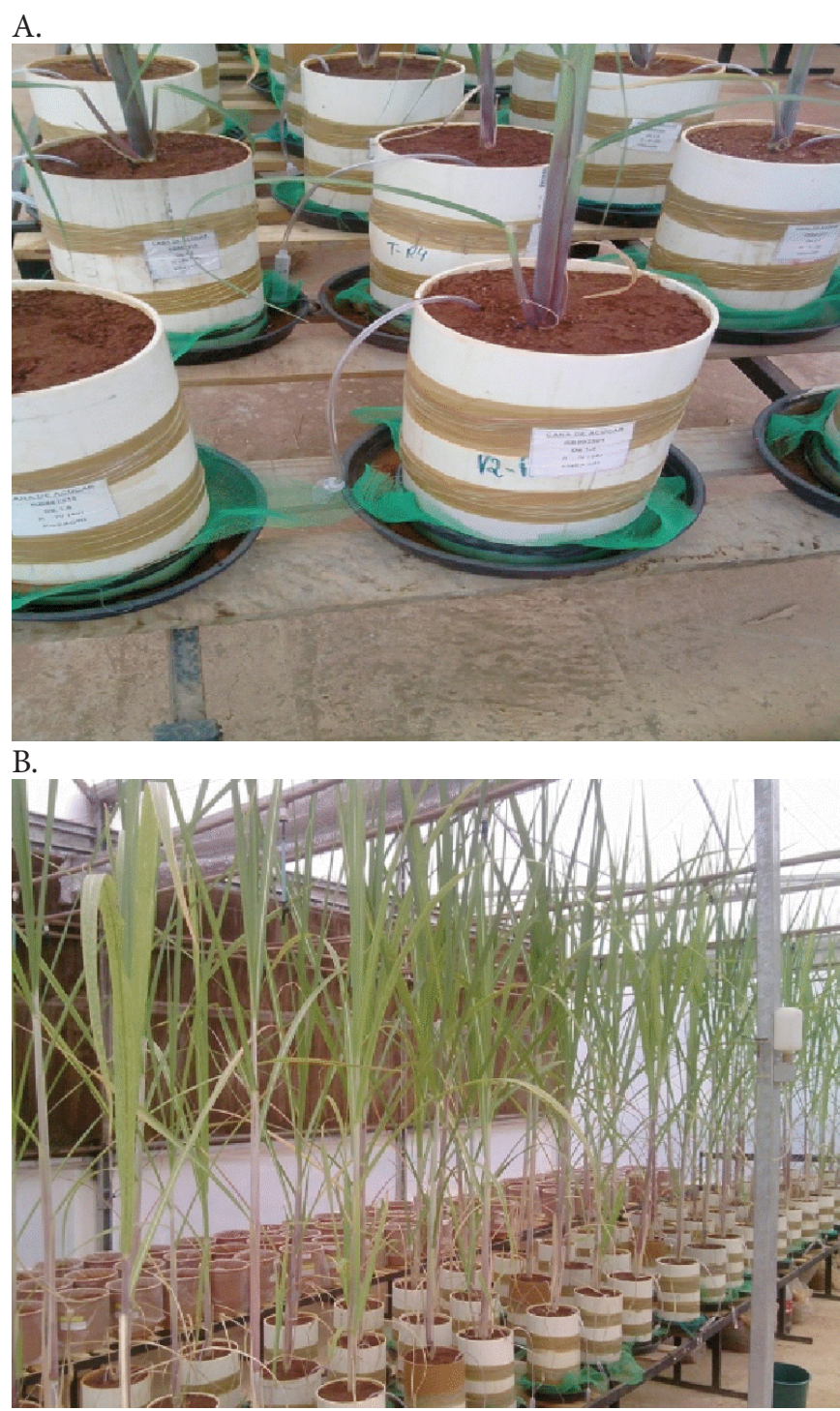

Figura 1. Unidade experimental (A) e visão geral do experimento (B)

da umidade ideal de compactação estabelecendo-se o valor de $16 \%$ à base de massa.

As Eqs. 1 e 2 foram utilizadas para determinação do peso de solo seco a ser utilizado em cada nível de compactação a partir da relação de densidade, ou seja, do peso do solo seco e do volume total.

$$
\begin{aligned}
\mathrm{Ds} & =\frac{\mathrm{MSS}}{\mathrm{VT}} \\
\mathrm{MSS} & =\mathrm{VT} \times \mathrm{Ds}
\end{aligned}
$$

em que:

$$
\begin{aligned}
& \text { MSS - massa do solo seco, } \mathrm{kg} \\
& \text { VT - volume total, } 3,140 \mathrm{dm}^{-3} \\
& \text { Ds - densidade do solo, } \mathrm{kg} \mathrm{dm}^{-3}
\end{aligned}
$$

A massa de solo colocada na prensa foi estabelecida de acordo com a umidade apresentada em cada vaso; a Eq. 3 foi 
dirigida para o cálculo da massa do solo úmido a ser utilizado (MSU):

$$
\mathrm{MSU}=\operatorname{MSS}(1+\theta \mathrm{m})
$$

em que:

$$
\begin{aligned}
& \text { MSU - massa do solo úmido, } \mathrm{g} \\
& \text { MSS - massa do solo seco, } \mathrm{g} \\
& \theta \mathrm{m} \text { - umidade à base de massa, \% }
\end{aligned}
$$

As mudas de cana-de-açúcar foram transplantadas para os vasos após 30 dias do plantio dos minitoletes logo após o estabelecimento da brotação. O delineamento utilizado foi o de blocos casualizados composto de três variedades (RB867515, RB931011 e RB002504) e cinco níveis de compactação (1,0; 1,2; 1,$4 ; 1,6 \mathrm{e} 1,8 \mathrm{Mg} \mathrm{m}^{-3}$ ) em quatro repetições totalizando 60 vasos.

Foi utilizado, em cada unidade experimental, um sistema sinalizador para o controle de irrigação, tipo Irrigás (Calbo \& Silva, 2005), composto de uma cápsula porosa (sensor) conectada a um tubo flexível e, na outra extremidade desse mesmo tubo, a uma seringa transparente $(3 \mathrm{~mL})$, que servia como dispositivo indicador da umidade do solo.

A cápsula foi instalada na profundidade de $80 \mathrm{~mm}$ próximo ao sistema radicular; as irrigações foram realizadas adicionando-se água na superfície do solo quando a umidade diminuía abaixo do valor crítico ( $25 \mathrm{kPa})$ indicado pelo sensor Irrigás; diariamente era realizada uma medição no final da tarde para monitorar a umidade de água no solo.

A curva característica de umidade do solo foi obtida utilizando-se o software SWCR (Dourado Neto et al., 2000) e os dados ajustados ao modelo proposto por van Genuchten (1980) de acordo com a Figura 2; já para o solo utilizado os valores de umidade na capacidade de campo e no ponto de murcha foram obtidos nas tensões de 10 e $1500 \mathrm{kPa}$, respectivamente.

$\mathrm{O}$ volume de água para atingir a umidade à capacidade de campo foi calculado por meio da Eq. 4:

$$
\mathrm{A}_{\mathrm{L}}=\left(\Delta \theta_{1}+\Delta \theta_{2}+\Delta \theta_{3}\right)
$$

em que:

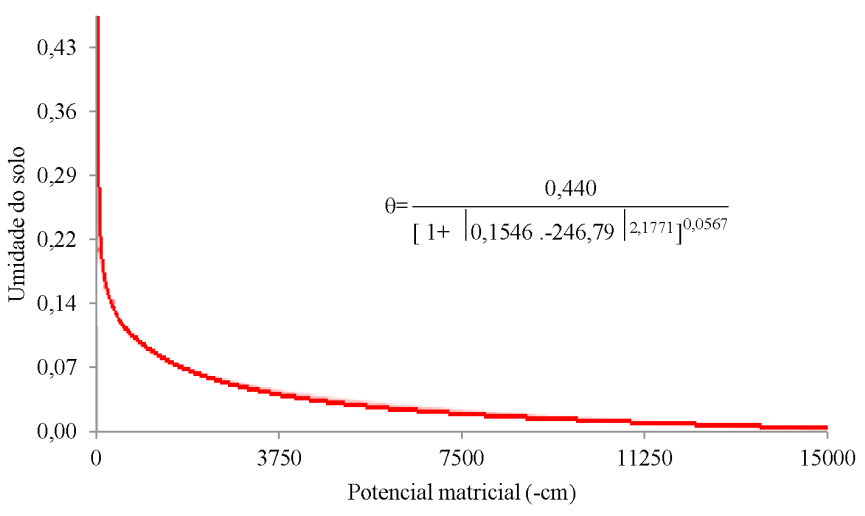

Fonte : van Genuchten (1980) e Dourado Neto et al. (2000)

Figura 2. Curva de retenção de água do solo
$\mathrm{A}_{\mathrm{L}} \quad$ - armazenamento de água, $\mathrm{cm}^{3} \mathrm{~cm}^{-3}$

$\Delta \theta_{1}$ e $\Delta \theta_{3}$ - diferença entre a umidade na capacidade de campo e a umidade equivalente à tensão de $25 \mathrm{kPa}$ na camada de densidade $1,0 \mathrm{Mg} \mathrm{m}^{-3}$ (1o e $3^{\circ}$ aneis)

$\Delta \theta_{2}$ - diferença entre a umidade na capacidade de campo e a umidade equivalente à tensão de $25 \mathrm{kPa}$ na camada compactada ( $2^{\circ}$ anel)

Para o cálculo da lâmina a ser aplicada nos vasos foi utilizada a Eq. 5:

$$
\mathrm{L}=\mathrm{A}_{\mathrm{L}} \times \mathrm{H}
$$

em que:

L - lâmina, cm

$\mathrm{A}_{\mathrm{L}} \quad$ - armazenamento de água, $\mathrm{cm}^{3} \mathrm{~cm}^{-3}$

$\mathrm{H}$ - altura do anel, $\mathrm{cm}$

enquanto o volume a ser aplicado foi calculado por meio da Eq. 6:

$$
\mathrm{V}=\mathrm{L} \times \mathrm{A}
$$

em que:

$\mathrm{V}$ - volume de água, $\mathrm{cm}^{3}$

L - lâmina aplicada, $\mathrm{cm}$

A - área da seção circular do tubo, $314,16 \mathrm{~cm}^{2}$

Os valores de água necessários para reposição da umidade à capacidade de campo encontrados para as densidades 1,0 ; 1,$2 ; 1,4 ; 1,6$ e 1,8 $\mathrm{Mg} \mathrm{m}^{-3}$ foram, respectivamente, 471, 502, 534, 565 e $597 \mathrm{~cm}^{3}$.

O corte das plantas ocorreu aos 93 dias após o plantio das mudas, na fase de perfilhamento da cultura; as variáveis analisadas foram: número de perfilhos, número de folhas, área foliar, massa seca das folhas, comprimento de colmos, massa seca de colmos e altura de plantas.

Os dados foram submetidos à análise de variância por meio do programa Sisvar (Ferreira, 2008) e pelo teste F, correlações simples e regressão. Para comparação das médias, utilizou-se o teste de Tukey a $5 \%$ de probabilidade.

\section{Resultados e Discussão}

As variáveis número de perfilhos, área foliar, massa seca de folhas, comprimento de colmos e massa seca de colmos apresentaram interação significativa entre as variedades de cana-de-açúcar e as densidades do solo.

Para o número de perfilhos houve interação significativa entre as variedades de cana-de-açúcar e as densidades do solo. A variedade RB002504 apresentou maior número de perfilhos na avaliação entre as variedades dentro das densidades $1,0,1,2$ e $1,4 \mathrm{Mg} \mathrm{m}^{-3}$ em relação às variedades RB867515 e RB931011 (Figura 3). 


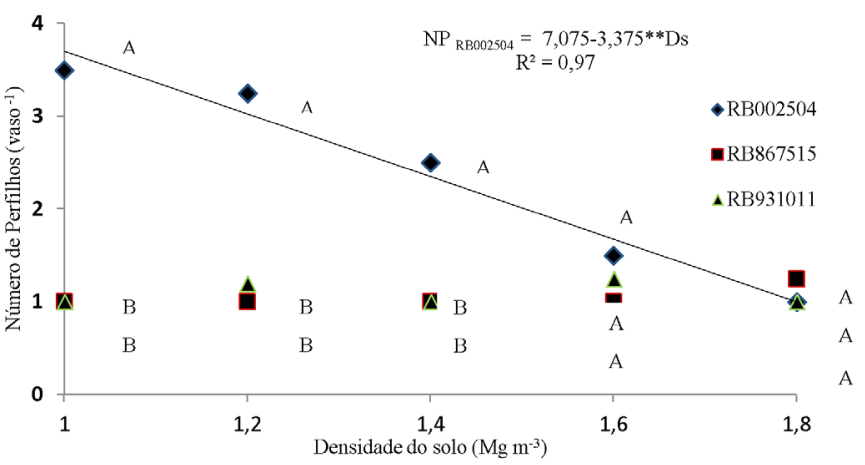

** Significante a 0,01 de probabilidade pelo teste $\mathrm{F}$

As médias seguidas de mesma letra fixando a densidade não diferem estatisticamente significante pelo teste de Tukey a 0,05 de probabilidade. Modelo de regressão linear ajustado para a RB002504

Figura 3. Número de perfilhos (NP) da cana-de-açúcar, variedades RB002504, RB867515 e RB931011

Pode-se observar, na variedade RB002504, que houve redução do número de perfilhos com o aumento dos níveis de compactação do solo cujo modelo foi descrito por equação linear de regressão. A redução foi de $73 \%$ na produção de perfilhos da densidade $1,0 \mathrm{Mg} \mathrm{m}^{-3}$ para a densidade $1,8 \mathrm{Mg}$ $\mathrm{m}^{-3}$. Esses resultados podem ser justificados pela redução da porosidade do solo devido ao aumento da densidade.

Os resultados para as variedades RB867515 e RB931011 corroboram com Camilotti et al. (2005) que não obtiveram diferença significativa na produção do número de perfilhos de cana-de-açúcar avaliando uma variedade RB. De acordo com Casagrande (1991), o perfilhamento é bastante variável entre as diversas variedades de cana-de-açúcar, dependendo das características genéticas de cada uma.

A resposta das variedades RB867515 e RB931011 para área foliar foi descrita por modelo quadrático de regressão quando então se obteve maior área foliar, respectivamente, com 3032,17 $\mathrm{cm}^{2}$ na densidade do solo $1,29 \mathrm{Mg} \mathrm{m}^{-3}$ e 2199,62 $\mathrm{cm}^{2}$ de área foliar na densidade 1,24 $\mathrm{Mg} \mathrm{m}^{-3}$ (Figura 4).

A área foliar é uma variável importante para a análise de crescimento e desenvolvimento sendo bem utilizada em estudos agronômicos; neste sentido, Wahid (2004) acrescenta que em condições de estresses ambientais genótipos sensíveis seriam mais prejudicados em virtude de reduzirem sua massa de folhas e sua área foliar.

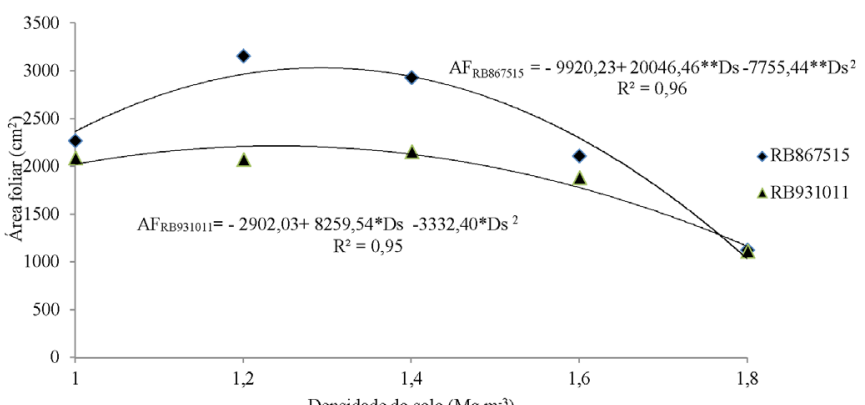

** Significante a 0,01 de probabilidade pelo teste F; * Significante a 0,05 de probabilidade pelo teste $\mathrm{F}$

Figura 4. Área foliar de cana-de-açúcar das variedades RB867515 e RB931011 em função das densidades do solo
Para a produção de massa seca de folhas constatou-se ajuste do modelo linear de regressão para a variedade RB002504 e ajuste do modelo quadrático de regressão para as variedades RB867515 e RB931011 (Figura 5).

Comparando a produção de massa seca de folhas da variedade RB002504 na densidade do solo $1,0 \mathrm{Mg} \mathrm{m}^{-3}$ com a produção de massa seca na densidade do solo $1,8 \mathrm{Mg} \mathrm{m}^{-3}$, podese observar uma redução de $37,77 \%$; com a limitação física do solo ocorreu diminuição na massa seca de folhas.

A variedade RB867515 apresentou máxima produção de massa seca de folhas na densidade $1,33 \mathrm{Mg} \mathrm{m}^{-3} \mathrm{com} 37,86 \mathrm{~g}$ e a variedade RB931011 na densidade $1,30 \mathrm{Mg} \mathrm{m}^{-3} \mathrm{com} 33,48 \mathrm{~g}$. Os resultados se assemelham aos encontrados por Bonfim-Silva et al. (2011) que também tiveram produção de massa seca da parte aérea do trigo ajustada ao modelo quadrático de regressão com sua máxima produção observada na densidade de $1,33 \mathrm{Mg} \mathrm{m}^{-3}$.

No comprimento de colmos a variedade RB002504 apresentou efeito significativo linear de regressão. Constatouse redução de $26,70 \%$ no comprimento do colmo da densidade do solo $1,0 \mathrm{Mg} \mathrm{m}^{-3}$ para a densidade $1,8 \mathrm{Mg} \mathrm{m}^{-3}$, as variedades RB867515 e RB931011 também apresentaram efeito da compactação, como mostra o modelo quadrático de regressão (Figura 6).

A variedade RB867515 apresenta maior comprimento de colmos com $1,08 \mathrm{~m}$ na densidade $1,30 \mathrm{Mg} \mathrm{m}^{-3} \mathrm{e}$ a variedade RB931011 na densidade $1,28 \mathrm{Mg} \mathrm{m}^{-3} \mathrm{com} \mathrm{1,23} \mathrm{m,} \mathrm{sendo} \mathrm{o} \mathrm{maior}$

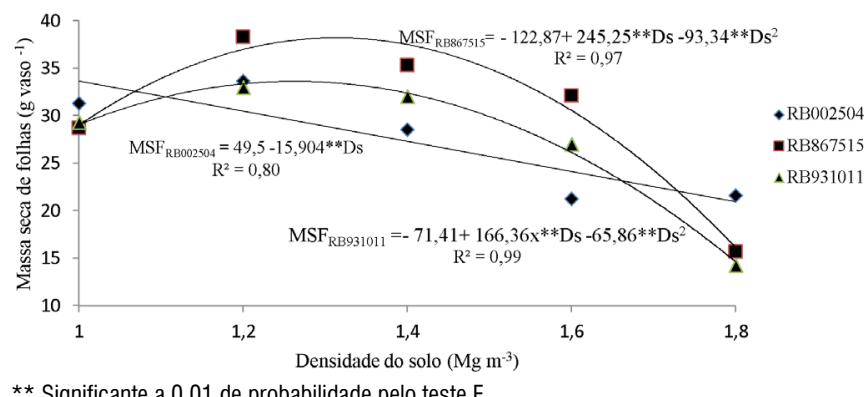

Figura 5. Massa seca de folhas de cana-de-açúcar nas variedades RB002504, RB867515 e RB931011 em função das densidades do solo

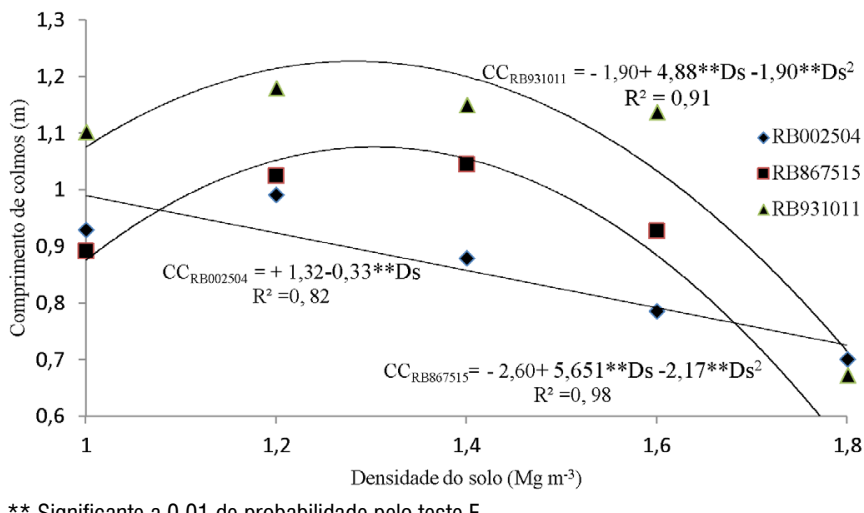

** Significante a 0,01 de probabilidade pelo teste $\mathrm{F}$

Figura 6. Comprimento de colmos de cana-de-açúcar nas variedades RB002504, RB867515 e RB931011 em função das densidades do solo 
comprimento entre as variedades. De acordo com Ferreira et al. (2007) variáveis relacionadas à produção de colmos apresentam maior relevância nos programas de melhoramento genético de cana-de-açúcar.

A produção de massa seca de colmos da variedade RB002504 apresentou redução de $54,37 \%$, em comparação com a densidade de 1,0 para 1,8 $\mathrm{Mg} \mathrm{m}^{-3}$ (Figura 7). Guimarães \& Moreira (2001) também verificaram, estudando a compactação do solo na cultura do arroz, que a massa seca da parte aérea foi reduzida com o aumento da densidade do solo em razão da menor absorção de nutrientes, como o Nitrogênio e o Potássio.

Na variedade RB867515 ocorreu a máxima produção de massa seca de colmos na densidade $1,33 \mathrm{Mg} \mathrm{m}^{-3}$ com $81,51 \mathrm{~g}$ enquanto a variedade RB931011 produziu 96,56 $\mathrm{g}$ de massa seca de colmos na densidade $1,19 \mathrm{Mg} \mathrm{m}^{-3}$.

Esta maior produção de massa seca de colmo pela variedade RB931011 pode ser explicada ao se comparar este resultado com os de comprimento de colmo, em que esta variedade também obteve o maior comprimento expressando potencial de desenvolvimento dos colmos.

A variável massa seca de raiz não apresentou efeito significativo das variedades em relação às densidades. Esses resultados podem, provavelmente, ser atribuídos à umidade do solo de vez que foram oferecidas as mesmas condições de umidade a todas as plantas. Durante o desenvolvimento da canade-açúcar a matéria seca radicular se distribui em função das condições ambientais (Machado, 1987) que, neste experimento, é limitada pela densidade do solo.

Os resultados corroboram com os encontrados por Calonego et al. (2011) que, comparando plantas de cobertura em solo compactados, não encontraram diferença significativa na produção de raízes mas Foloni et al. (2003) obtiveram resultados semelhantes com cultivares de milho.

A compactação apresentou efeito significativo nas variedades tendo os resultados apresentado um modelo linear de regressão (Figura 8). Comparando a produção de massa seca de raiz das variedades na densidade do solo $1,0 \mathrm{Mg} \mathrm{m}^{-3}$ com a produção na densidade do solo $1,8 \mathrm{Mg} \mathrm{m}^{-3}$, pode-se observar redução de $50,42 \%$. Freddi et al. (2007) também verificaram redução na matéria seca de raiz em plantas de milho com o aumento da densidade do solo.

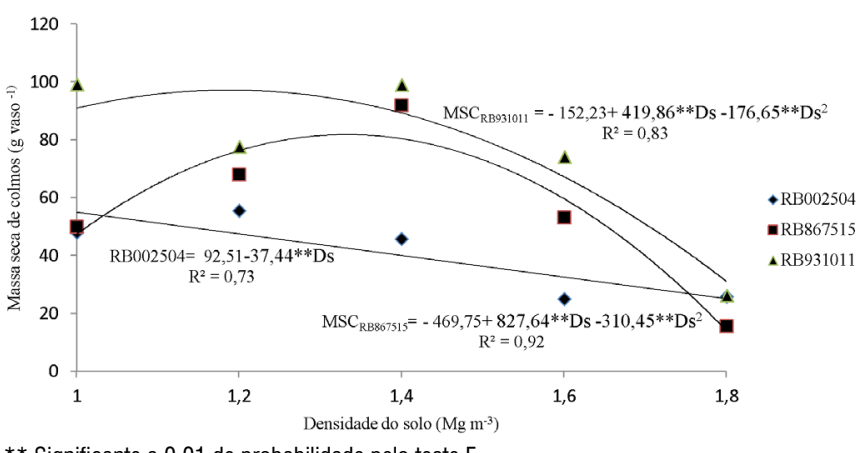

** Significante a 0,01 de probabilidade pelo teste $\mathrm{F}$

Figura 7. Massa seca de colmos de cana-de-açúcar nas variedades RB002504, RB867515 e RB931011 em função das densidades do solo

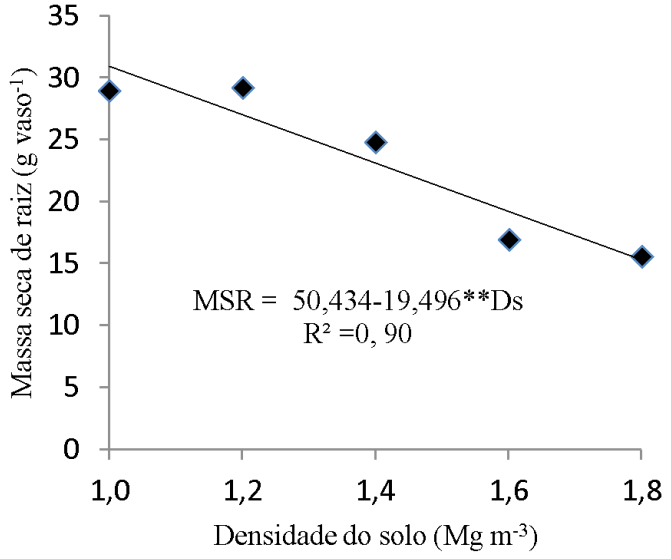

* Significante a 0,01 de probabilidade pelo teste $F$

Figura 8. Massa seca de raiz das variedades RB002504, RB867515 e RB931011 em função das densidades do solo

Segundo Borges et al. (1999) altos valores de densidade do solo prejudicam o desenvolvimento das plantas pela restrição à penetração de raízes. O maior desenvolvimento do sistema radicular pode proporcionar aumento na absorção de água e nutrientes minerais aumentando a área foliar e o vigor das plantas (Tavares et al., 2007). Os resultados apresentados neste trabalho demonstram que as raízes apresentaram melhor desenvolvimento na densidade $1,0 \mathrm{Mg} \mathrm{m}^{-3}$.

\section{Conclusões}

1. A variedade RB002504 produz bom perfilhamento, mas não apresenta bom desenvolvimento de colmos em relação às outras variedades.

2. A variedade RB867515 apresenta bom desenvolvimento de área foliar demonstrando eficiência fotossintética que favorece o estádio vegetativo inicial da cultura.

3. A variedade RB931011 apresenta maior massa seca e comprimento de colmos evidenciando ser tolerante à compactação do solo.

\section{Literatura Citada}

Bonelli, E. A.; Bonfim-Silva, E. M.; Cabral, C. E. A.; Campos, J. J.; Scaramuzza, W. L. M.; Polizel, A. C. Compactação do solo: Efeitos nas características produtivas e morfológicas dos capins Piatã e Mombaça. Revista Brasileira de Engenharia Agrícola e Ambiental, v.15, p.264-269, 2011.

Bonfim-Silva, E. M.; Anicésio, E. C. A.; Silva, F. C. M.; Dourado, L. G. A.; Aguero, N. F. Compactação do solo na cultura do trigo em Latossolo do cerrado. Enciclopédia Biosfera, v.7, p.1-6, 2011.

Borges, E. N.; Lombardi Neto, F.; Corrêa, G. F. Borges, E. V. S. Alterações físicas introduzidas por diferentes níveis de compactação em Latossolo Vermelho Escuro textura média. Pesquisa Agropecuária Brasileira, v.34, p.663-1667, 1999. 
Calbo A. G.; Silva W. L. C. Sistema Irrigas para manejo de irrigação: Fundamentos, aplicações e desenvolvimentos. Brasília: Embrapa Hortaliças, 2005. 174p.

Calonego J. C; Gomes, T. C.; Santos, C. H.; Tiritan, C. S. Desenvolvimento de plantas de cobertura em solo compactado. Biocência, v.27, p.289-296. 2011.

Camilotti, F.; Andrioli I.; Dias F. L. F.; Casagrande A. A.; Silva. A. R.; Mutton, M. A.; Centurion, J. F. Efeito prolongado de sistemas de preparo do solo com e sem cultivo de soqueira de cana crua em algumas propriedades físicas do solo. Engenharia Agrícola, v.25, p.189-198, 2005.

Casagrande, A. A. Tópicos de morfologia e fisiologia da canade-açúcar. Jaboticabal: FUNEP, 1991. 157p

Cronquist, A. An integrated system of classification of flowering plants. New York: Columbia University Press, 1981. 1262p.

Dourado Neto, D.; Nielsen, D. R.; Hopmans, J. W.; Reichardt, K.; Bacchi, O. O. S. Software to model soil water retention curves (SWRC, version 2.0). Scientia Agrícola, v.57, p.191$192,2000$.

Ferreira, D. F. SISVAR: Um programa para análises e ensino de estatística. Revista Symposium, v.6, p.36-41, 2008.

Ferreira, F. M.; Barros, W. S.; Silva, F. L.; Barbosa, H. P.; Cruz, C. D.; Bastos, I. T. Relações fenotípicas e genotípicas entre componentes de produção em cana-de-açúcar. Bragantia, v.66, p.605-610, 2007.

FNP Consultoria e Comércio. Cana-de-açúcar. In: Agrianual 2011: Anuário da agricultura Brasileira. São Paulo, 2011. 482p.

Foloni, J. S.; Calonego, J. C.; Lima, S. L. Efeito da compactação do solo no desenvolvimento aéreo e radicular de cultivares de milho. Pesquisa Agropecuária Brasileira, v.38, p.947953, 2003.
Freddi, O. S.; Centurion, J. F.; Beutler, A. N.; Aratani, R. G.; Leonel, C. L. Compactação do solo no crescimento radicular e produtividade da cultura do milho. Revista Brasileira de Ciência do Solo, v.31. p.627-636. 2007.

Guimarães, C. M.; Moreira, J. A. A. Compactação do solo na cultura do arroz de terras altas. Pesquisa Agropecuária Brasileira, v.36, p.703-707, 2001.

Machado, E. C. Fisiologia da produção de cana-de-açúcar. In: Paranhos, S. B. Cana-de-açúcar: Cultivo e utilização. Campinas: Fundação Cargill, v.1, 1987. p.56-87.

Machado, E. C.; Pereira, A. R.; Fahl, J. L.; Arruda, H. V.; Cione, J. Análise quantitativa de crescimento de quatro variedades de milho em três densidades de plantio, através de funções matemáticas ajustadas. Pesquisa Agropecuária Brasileira, v.17, p.1323-1329,1982.

Raij, B. van; Cantarela, H.; Quaggio, J. A; Furlani, A. M. C. Recomendações de adubação e calagem para o estado de São Paulo. 2.ed. Campinas: Instituto Agronômico e Fundação IAC, 1996. 285p. Boletim Técnico, 100.

Severiano, E. C.; Oliveira, G. C.; Curi, N.; Dias Júnior, M. S. Potencial de uso e qualidade estrutural de dois solos cultivados com cana-de-açúcar em Goianésia, GO. Revista Brasileira de Ciência do Solo, v.33, p.159-168, 2009.

Tavares, S.; Castro, P. R. C.; Ribeiro, R. V.; Aramaki, P. H. Avaliação dos efeitos fisiológicos de thiamethoxam no tratamento de sementes de soja. Revista de Agricultura, v.82, p.48-67, 2007.

van Genuchten, M. T. A closed form equation for predicting the hydraulic conductivity of unsaturated soils. Soil Science Society of America Journal, v.44, p.892-898, 1980.

Wahid, A. Analysis of toxic and osmotic effects of sodium chloride on leaf growth and economic yield of sugarcane. Botanical Bulletin of Academia Sinica, v.45, p.133-141, 2004. 